\title{
Nuclear expression of sox11 is highly associated with mantle cell lymphoma but is independent of $t(11 ; 14)(q 13 ; q 32)$ in non-mantle cell B-cell neoplasms
}

\author{
Yi-Hua Chen ${ }^{1, *}$, Juehua Gao ${ }^{1}$, Guang Fan² and LoAnn C Peterson ${ }^{1}$ \\ ${ }^{1}$ Department of Pathology, Northwestern University Feinberg School of Medicine, Chicago, IL, USA and \\ ${ }^{2}$ Department of Pathology, Oregon Health and Science University, Portland, OR, USA
}

\begin{abstract}
Sox11 is a transcription factor involved in embryonic neurogenesis and tissue remodeling. Its role in lymphopoiesis is presently unknown. Recent studies have shown the nuclear expression of sox11 in mantle cell lymphoma, which raises the question about its possible association with $t(11 ; 14)(q 13 ; q 32)$, the genetic hallmark of mantle cell lymphoma leading to the overexpression of cyclin D1. In this study, we examined sox11 expression in 211 cases of B-cell neoplasms by immunohistochemistry, and evaluated its association with $t(11 ; 14)$ and overexpression of cyclin D1. Nuclear staining of sox11 was observed in 54 of $57(95 \%)$ mantle cell lymphomas, including 52 of $53(98 \%)$ classical and 2 of 4 variant types. Two of the three mantle cell lymphomas negative for nuclear sox11 staining were analyzed and were positive for $t(11 ; 14)$. All other B-cell lymphomas (114 cases) showed variable positive staining in the cytoplasm, but no nuclear positivity. Sox11 was then examined in plasma cell myeloma and hairy cell leukemia as a subset of plasma cell myeloma carry $t(11 ; 14)$ and overexpress cyclin D1, and cyclin D1 is overexpressed in a subset of hairy cell leukemia independent of $t(11 ; 14)$. We found no nuclear staining of sox11 in 30 plasma cell myelomas examined, including 12 cases with $t(11 ; 14)(q 13 ; q 32)$. It is interesting that intense nuclear staining of sox11 was present in a subset of hairy cell leukemias (5 of 10), and was associated with the overexpression of cyclin D1. Our results indicate that the nuclear expression of sox11 is highly associated with mantle cell lymphoma, but is independent of $t(11 ; 14)(q 13 ; q 32)$ in non-mantle cell B-cell neoplasms. Its association with the overexpression of cyclin D1 in hairy cell leukemia suggests that sox 11 may be involved in the upregulation of cyclin D1 in this leukemia. Modern Pathology (2010) 23, 105-112; doi:10.1038/modpathol.2009.140; published online 2 October 2009
\end{abstract}

Keywords: sox11; cyclin D1; mantle cell lymphoma; plasma cell myeloma; hairy cell leukemia; immunohistochemistry

Mantle cell lymphoma accounts for approximately $3-10 \%$ of non-Hodgkin lymphomas and is considered one of the most aggressive B-cell lymphomas. The genetic hallmark of mantle cell lymphoma is $\mathrm{t}(11 ; 14)(\mathrm{q} 13 ; \mathrm{q} 32)$ that juxtaposes the CCND1 gene encoding cyclin D1 to immunoglobulin heavy chain gene, leading to the overexpression of cyclin D1. ${ }^{1}$ The upregulation of cyclin D1 has a pivotal role in

${ }^{*}$ Correspondence: Dr Y-H Chen, MD, Department of Pathology, Northwestern University Feinberg School of Medicine, 251 East Huron, Feinberg 7-209A, Chicago, IL 60611, USA.

E-mail: y-chen5@northwestern.edu

Received 16 June 2009; revised 21 August 2009; accepted 24 August 2009; published online 2 October 2009 the pathogenesis of mantle cell lymphoma. However, additional oncogenetic events are required for the complete development of the tumor., ${ }^{1,2}$ DNA microarrays and gene expression profiling have shown that several genes are differentially expressed in mantle cell lymphoma compared with normal lymphoid tissue. ${ }^{3-5}$ Recently, sox11, a transcription factor involved in embryonic neurogenesis and tissue remodeling, has been found to be expressed in the nuclei of mantle cell lymphoma cells. ${ }^{6,7}$ This intriguing finding raises the question about the possible association between the nuclear expression of sox11 and $\mathrm{t}(11 ; 14)(\mathrm{q} 13 ; \mathrm{q} 32) .{ }^{6}$

The SRY (sex-determining region Y)-box11 (SOX11) gene is mapped to chromosome 2p25 and 
belongs to the $S R Y$-related high mobility group (HMG) box (SOX) gene family characterized by containing the HMG domain with high identity to the HMG domain in $S R Y{ }^{8}$ More than $20 S O X$ genes have been identified in humans and mice, and are divided into 8 groups according to the degree of homology within and outside the HMG domain. ${ }^{9,10}$ The $S O X$ gene family encodes a group of transcription factors that have critical roles in the determination of cell fate and differentiation. ${ }^{9-11}$ Evidence suggests that SOX11 is critical for embryonic neurogenesis and tissue remodeling. ${ }^{8,11,12}$ However, the data on the roles of $S O X$ genes in hematopoiesis are very limited. To date, SOX4 is the only gene in the family that has been found to have an important role in the early B- and T-cell development. ${ }^{13,14}$ SOX11 belongs to the same group and shares high sequence homology with $S O X 4,{ }^{15}$ but its role in lymphopoiesis remains to be elucidated.

In this study, we examined sox11 expression in a large series of B-cell neoplasms by immunohistochemistry to investigate whether nuclear staining of sox11 can serve as a useful diagnostic marker for mantle cell lymphoma. We further investigated the association of the nuclear expression of sox11, $\mathrm{t}(11 ; 14)(\mathrm{q} 13 ; \mathrm{q} 32)$ and overexpression of cyclin D1. Our results indicate that the nuclear expression of sox11 is highly associated with mantle cell lymphoma, but is independent of $t(11 ; 14)(q 13 ; q 32)$ in non-mantle cell B-cell neoplasms. We also showed for the first time that in addition to mantle cell lymphoma, nuclear expression of sox11 is also present in a subset of hairy cell leukemia and is associated with overexpression of cyclin D1. The significance of these findings is discussed.

\section{Materials and methods}

\section{Case Selection}

This study was approved by the Institutional Review Boards of the Northwestern Memorial Hospital and Oregon Health and Science University. Cases diagnosed as mantle cell lymphoma between January 1994 and September 2008 were searched from the database in the Department of Pathology at the Northwestern Memorial Hospital. A total of 57 mantle cell lymphomas in which the diagnosis was confirmed by overexpression of cyclin D1 and/or the presence of $\mathrm{t}(11 ; 14)-C C N D 1 / I g H$ translocation were retrieved. An additional 114 cases of other subtypes of B-cell lymphomas were also retrieved from the Northwestern Memorial Hospital, including 50 chronic lymphocytic leukemia/small lymphocytic lymphomas, 22 follicular lymphomas, 12 marginal zone lymphomas and 30 diffuse large B-cell lymphomas. A total of 30 formalin-fixed and paraffin-embedded bone marrow biopsy samples of plasma cell myeloma and 10 hairy cell leukemias were obtained from the Oregon Health and Science University.

\section{Immunohistochemistry}

Immunohistochemical stains were performed on whole tissue sections. After antigen retrieval in a Decloaking Chamber (Biocare Medical, Concord, CA, USA) using DAKO antigen retrieval solution ( $\mathrm{pH}$ 6.0), the tissue sections were automatically stained for sox11 on DAKO Autostainer (DAKO, Carpinteria, CA, USA) using the IVIEW detection system. Antigen retrieval and immunohistochemical stain for cyclin D1 were performed automatically on Benchmarker XT (Ventana Medical System, Tucson, AZ, USA) using the Advanced HRP detection system. The primary antibodies used were as follows: polyclonal anti-sox11 at a dilution of 1:50 (Atlas Antibodies, Stockholm, Sweden) and polyclonal anti-cyclin D1 at 1:25 dilution (NeoMarkers, Fremont, CA, USA). Reactive tonsillar tissue and normal lymph node were used as controls.

\section{Fluorescence In Situ Hybridization}

Interphase fluorescence in situ hybridization (FISH) for $\mathrm{t}(11 ; 14)-C C N D 1 / \mathrm{IgH}$ fusion in mantle cell lymphoma was performed on touch imprints or paraffinembedded tissues at Mayo Medical Laboratories (Rochester, MN, USA) using the dual-color and dual-fusion probes for CCND1 (11q13) and IgH (14q32) (Abbott Laboratories, Des Plaines, IL, USA). Interphase FISH analysis of plasma cell myeloma was performed on the cytospin preparations of bone marrow aspirates at the Oregon Health and Science University. For the CCND1/IgH fusion, the same dual-color and dual-fusion probes were used. Briefly, the slides were placed at $72{ }^{\circ} \mathrm{C}$ for $2 \mathrm{~min}$, and then hybridized overnight with the denatured probes at $37^{\circ} \mathrm{C}$. After washing in $0.4 \times \mathrm{SSC} / 0.3 \% \mathrm{NP}-40$ at $72{ }^{\circ} \mathrm{C}$ for $2 \mathrm{~min}$, followed by cooling at room temperature in $2 \times$ SSC $/ 0.1 \%$ NP-40, the slides were air dried in darkness and mounted in DAPI II counter stain.

\section{Results}

\section{Sox11 Expression in B-Cell Lymphomas}

A total of 57 formalin-fixed and paraffin-embedded mantle cell lymphomas with diagnosis confirmed at the initial work-up by overexpression of cyclin D1 and/ or by the presence of $t(11 ; 14)(q 13 ; q 32)$ were retrieved for the study. These cases included 53 classical and 4 variant mantle cell lymphomas (3 blastoid and 1 pleomorphic). Before examination of sox11, immunohistochemical stain for cyclin D1 was performed on all retrieved mantle cell lymphomas, and positive nuclear staining was seen in all 57 cases. No cyclin D1-negative mantle cell lymphoma was identified in this series. In all, 16 cases (14 classical and 2 variant) were analyzed by FISH and were positive for $\mathrm{t}(11 ; 14)$.

In normal lymphoid tissues, positive staining for sox11 was seen only in the cytoplasm of germinal 
Table 1 Nuclear expression of sox11 in B-cell neoplasms

\begin{tabular}{|c|c|c|}
\hline B-cell neoplasms & $\begin{array}{c}\text { Number of } \\
\text { cases }\end{array}$ & $\begin{array}{l}\text { Nuclear } \\
\text { expression } \\
\text { of sox11 }\end{array}$ \\
\hline \multicolumn{3}{|l|}{ Mantle cell lymphoma $(\mathrm{n}=57)$} \\
\hline Classical & 53 & 52 \\
\hline Variant & 4 & 2 \\
\hline $\begin{array}{l}\text { Chronic lymphocytic leukemia/small } \\
\text { lymphocytic lymphoma }(\mathrm{n}=50)\end{array}$ & 50 & 0 \\
\hline Follicular lymphoma $(\mathrm{n}=22)$ & 22 & 0 \\
\hline Marginal zone lymphoma $(\mathrm{n}=12)$ & 12 & 0 \\
\hline Diffuse large B-cell lymphoma $(\mathrm{n}=30)$ & 30 & 0 \\
\hline \multicolumn{3}{|l|}{ Hairy cell leukemia $(\mathrm{n}=10)$} \\
\hline Cyclin D1+ & 5 & 5 \\
\hline Cyclin D1- & 5 & 0 \\
\hline \multicolumn{3}{|l|}{ Plasma cell myeloma $(\mathrm{n}=30)$} \\
\hline t(11;14)/Cyclin D1+ & 12 & 0 \\
\hline +11/Cyclin D1+a & 10 & 0 \\
\hline +11/Cyclin D1- & 1 & 0 \\
\hline Nl/Cyclin D1- ${ }^{\mathrm{b}}$ & 6 & 0 \\
\hline Nl/Cyclin D1+ & 1 & 0 \\
\hline
\end{tabular}

${ }^{a}+11$ : Presumed trisomy 11 based on abnormal FISH pattern of 2 green (14q32) and 3 orange (11q13) signals.

${ }^{\mathrm{b}} \mathrm{Nl}$ : FISH negative for both $\mathrm{t}(11 ; 14)$ and +11 .

center cells. However, homogeneous nuclear staining of sox11 was observed in 54 of $57(95 \%)$ mantle cell lymphomas, including 52 of $53(98 \%)$ classical and 2 of 4 variant types (Table 1 and Figure 1). One classical and two blastoid mantle cell lymphomas showed predominantly cytoplasmic staining; the nuclei were negative. These two blastoid cases were analyzed by FISH and were positive for $\mathrm{t}(11 ; 14)$.

All other B-cell lymphomas examined, including 50 chronic lymphocytic leukemia/small lymphocytic lymphomas, 22 follicular lymphomas, 12 marginal zone lymphomas and 30 diffuse large B-cell lymphomas, displayed variable sox11 staining only in the cytoplasm; the nuclei were completely negative (Table 1 and Figure 1). In diffuse large B-cell lymphomas, the majority of the neoplastic cells showed strong cytoplasmic granular staining (Figure 1). Other types of B-cell lymphomas showed variable weak cytoplasmic staining in the non-transformed neoplastic lymphocytes, whereas the transformed lymphocytes such as prolymphocytes in chronic lymphocytic leukemia/small lymphocytic lymphomas and centroblasts in follicular lymphomas showed strong cytoplasmic granular staining similar to diffuse large B-cell lymphoma (Figure 1).

\section{Sox11 Expression in Plasma Cell Myeloma and Correlation with $t(11 ; 14)$ and Overexpression of Cyclin D1}

To further investigate the possible association among the nuclear expression of sox11, $\mathrm{t}(11 ; 14)(\mathrm{q} 13 ; \mathrm{q} 32)$ and the overexpression of cyclin D1, 30 plasma cell myelomas were selected for the study on the basis of the FISH results, including 12 cases positive for $\mathrm{t}(11 ; 14)$ (q13; $\mathrm{q} 32)$, 11 with trisomy $11(+11)$ and 7 negative for both abnormalities. Immunohistochemical stain for cyclin D1 showed strong nuclear staining in 12 of $12(100 \%)$ cases with $\mathrm{t}(11 ; 14), 10$ of 11 (91\%) with +11 and in 1 of 7 (14\%) negative for both abnormalities (Table 1). Diffuse strong cyclin D1 staining correlated with $t(11 ; 14)$, whereas intermediate staining in a subset of plasma cells $(30-50 \%)$ was associated with +11 (Figure 2). However, immunohistochemical stain for sox11 showed no nuclear staining in all cases of plasma cell myelomas examined, including 12 cases with $\mathrm{t}(11 ; 14)$; variable positive granular staining was observed only in the cytoplasm (Table 1 and Figure 2).

\section{Sox11 Expression in Hairy Cell Leukemia and Correlation with Overexpression of Cyclin D1}

Sox11 was examined in 10 formalin-fixed and paraffin-embedded bone marrow core biopsy samples obtained from patients with hairy cell leukemia and compared with cyclin D1 expression. The diagnosis of hairy cell leukemia was established on the basis of morphological findings, clinical information and characteristic immunophenotype. ${ }^{1}$ Six cases showed extensive $(>70 \%)$ and four showed moderate $(20-40 \%)$ bone marrow involvement. Immunohistochemical stain for sox11 showed intense nuclear staining in 5 of $10(50 \%)$ cases. Surprisingly, these five cases also showed strong nuclear staining of cyclin D1. The remaining five cyclin D1-negative hairy cell leukemias showed granular staining of sox11 only in the cytoplasm; the nuclei were completely negative (Table 1 and Figure 3).

\section{Discussion}

SOX11 is normally expressed throughout the developing nervous system of human embryos and is required for neuron survival and neurite growth., ${ }^{8,16-18}$ However, the data on the roles of SOX genes in hematopoiesis are very limited. To date, SOX4 is the only gene in the family that has been found to have a key role in lymphopoiesis. B-cell development is blocked at the pro-B-cell stage in Sox4-deficient mice. ${ }^{14}$ Although SOX11 shares high identity with $S O X 4$, its role in lymphopoiesis remains to be elucidated. Similar to many other developmental regulatory genes, the improper expression and function of $S O X$ genes have been linked to various human cancers. ${ }^{19}$ SOX11 and SOX4 were found strongly expressed in several neurological malignancies, such as medulloblastoma and glioblastoma. ${ }^{20,21}$ High-throughput retroviral tagging identified that SOX4 expression was elevated in 


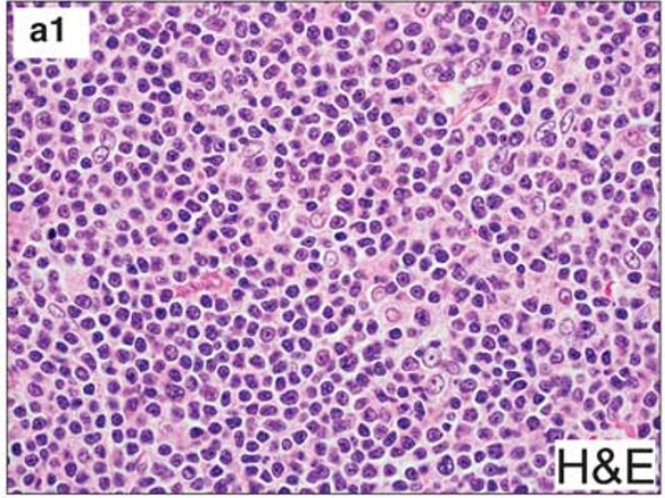

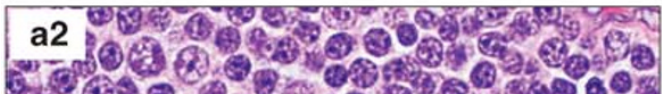

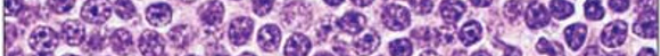

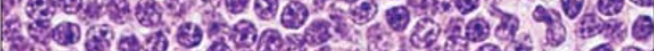

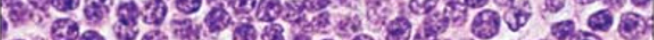

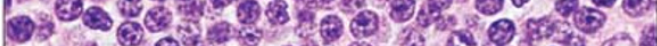

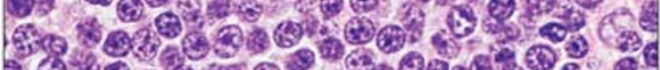

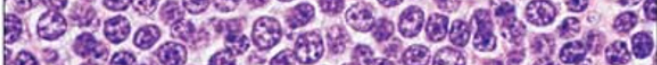

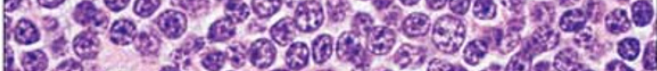

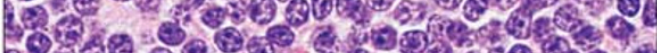

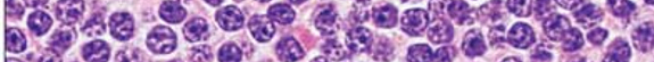

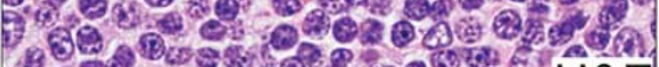
890
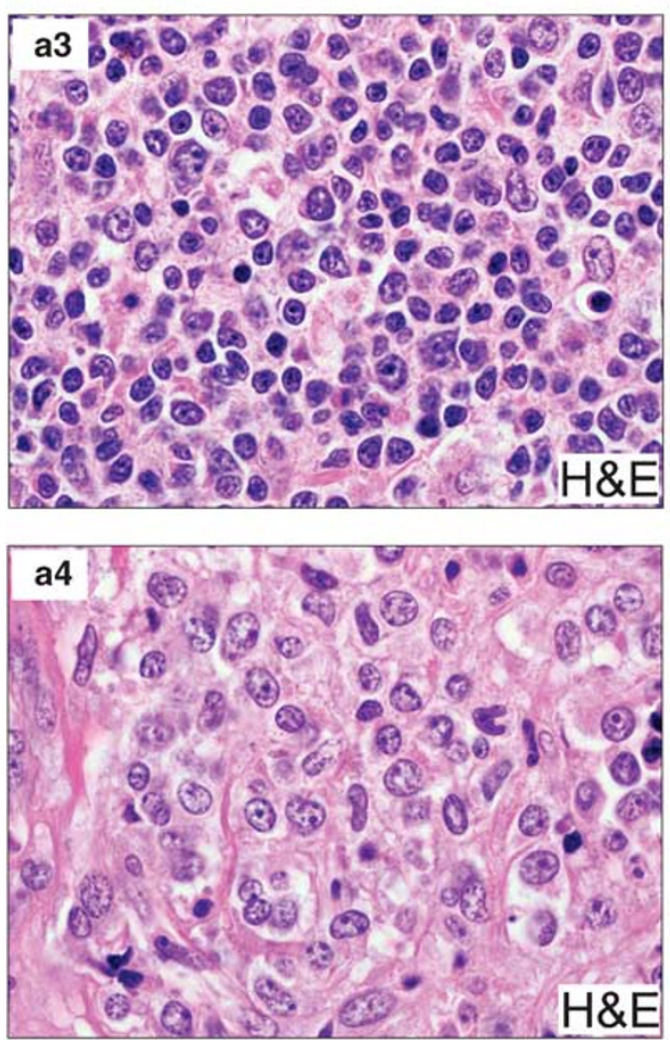
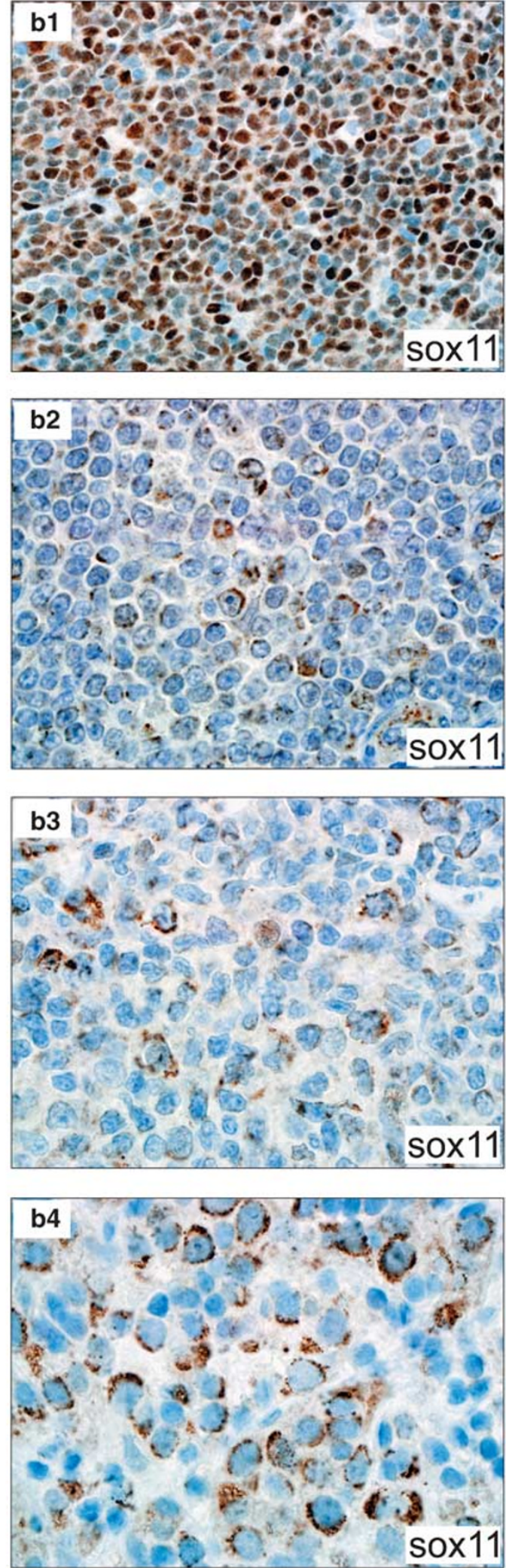

Figure 1 Sox11 expression in B-cell lymphomas. H\&E (left) and immunohistochemical stain for sox11 (right) in representative cases of B-cell lymphomas. Mantle cell lymphoma showed intense homogeneous nuclear staining of sox11 ( $\times 600)(\mathbf{1 a}, \mathbf{b})$. Chronic lymphocytic leukemia/small lymphocytic lymphoma (2a, b), follicular lymphoma $(\mathbf{3 a}, \mathbf{b})$ and diffuse large B-cell lymphoma (4a, b) displayed variable sox11 staining only in the cytoplasm; the nuclei were completely negative $(\times 1000)$. 

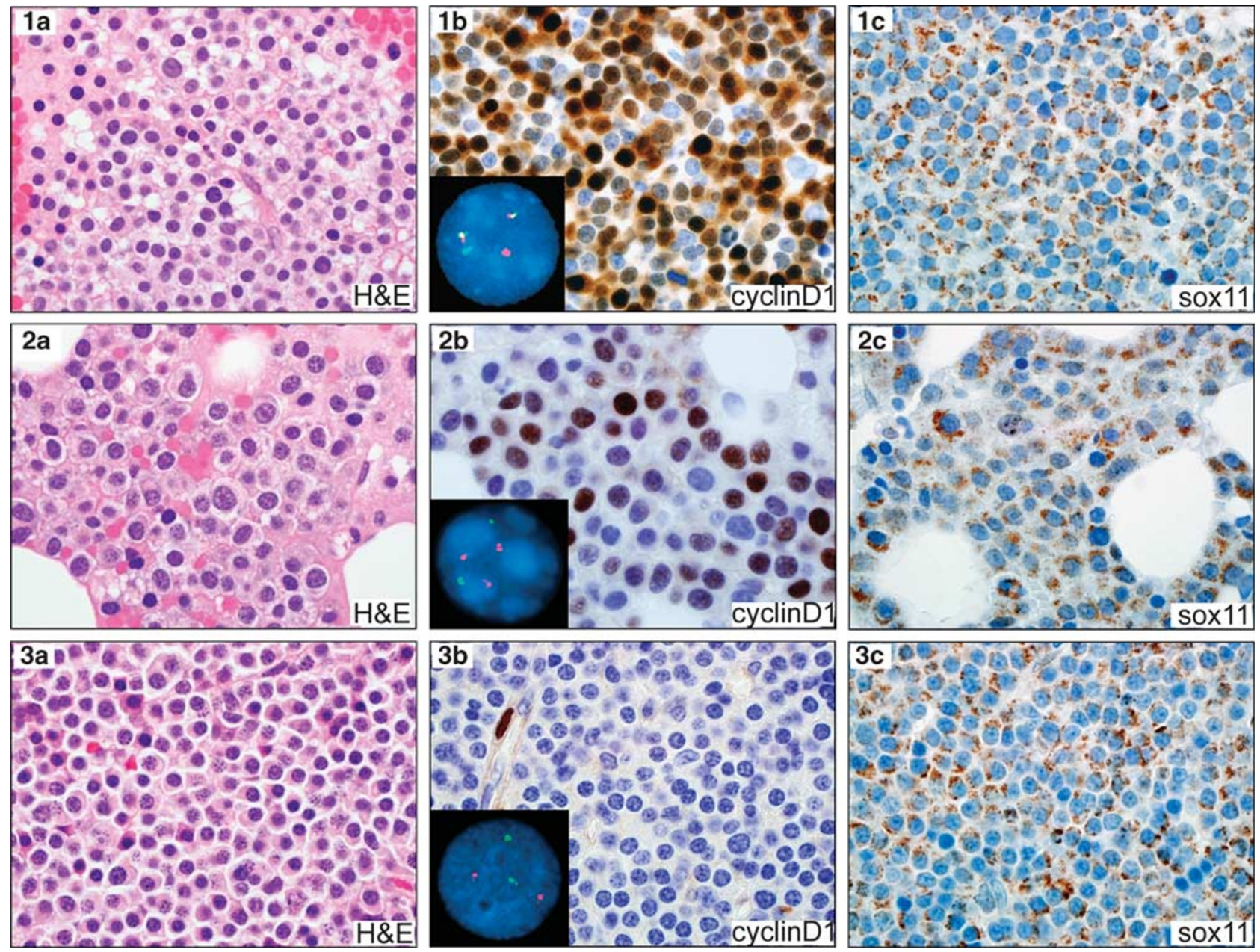

Figure 2 Sox11 expression in plasma cell myeloma. H\&E (left), immunohistochemical stain for cyclin D1 (middle), fluorescence in situ hybridization (FISH) for t(11;14)-CCND1/IgH translocation (middle inset) and immunohistochemical stain for sox11 (right) in representative cases of plasma cell myelomas $(\times 1000)$. FISH: orange signal representing CCND1gene at chromosome 11q13, green signal representing $I g H$ gene at $14 \mathrm{q} 32$ and yellow signal representing fusion of $C C N D 1$ and $I g H$. (1a-c) Plasma cell myeloma positive for t(11;14) showed diffuse strong nuclear positivity for cyclin D1, but was negative for nuclear staining of sox11. Positive granular staining of sox11 was seen only in the cytoplasm. (2a-c) Plasma cell myeloma with +11 showed partial positive nuclear staining of cyclin D1, and negative nuclear staining for sox11. (3a-c) Plasma cell myeloma negative for both $\mathrm{t}(11 ; 14)$ and +11 was negative for cyclin D1 and nuclear staining of sox11. The cells showing positive nuclear staining of cyclin D1 were endothelial cells (3b).

mouse splenic marginal zone lymphoma and associated with tumor progression. ${ }^{22}$

In this study, we showed that the nuclear expression of sox11 is highly associated with mantle cell lymphoma among B-cell lymphomas. Homogeneous nuclear staining of sox11 was observed in 54 of 57 (95\%) mantle cell lymphomas, including 52 of 53 (98\%) classical and 2 of 4 variant mantle cell lymphomas. All other types of B-cell lymphomas, including 50 chronic lymphocytic leukemia/small lymphocytic lymphomas, 22 follicular lymphomas, 12 marginal zone lymphomas and 30 diffuse large B-cell lymphomas, were completely negative for nuclear sox11 staining. The results indicate that sox11 is a useful immunohistochemical marker for mantle cell lymphoma. We did not identify cyclin D1-negative mantle cell lymphomas in this series, but one such case was reported in the study by
Ek et $a l^{6}$ and was positive for nuclear sox11 staining. Therefore, sox11 could be particularly valuable in the diagnosis of this subset of cases. However, this needs to be confirmed by studies on a larger number of cyclin D1-negative mantle cell lymphoma cases. Wang et al reported in their series that 5 of 53 mantle cell lymphomas were negative for nuclear staining of sox11; none of these cases were blastoid variant. These patients had shorter survival compared with mantle cell lymphomas with nuclear sox11 staining. ${ }^{7}$ Ek et al evaluated sox11 expression in 18 whole tissue sections of mantle cell lymphomas, including 16 classical and 2 blastoid mantle cell lymphomas. One case was negative for nuclear sox11 staining, and this case was a blastoid variant. ${ }^{6}$ In this study, two of the three mantle cell lymphomas negative for nuclear sox11 staining were blastoid variants. Our results indicate that nuclear 

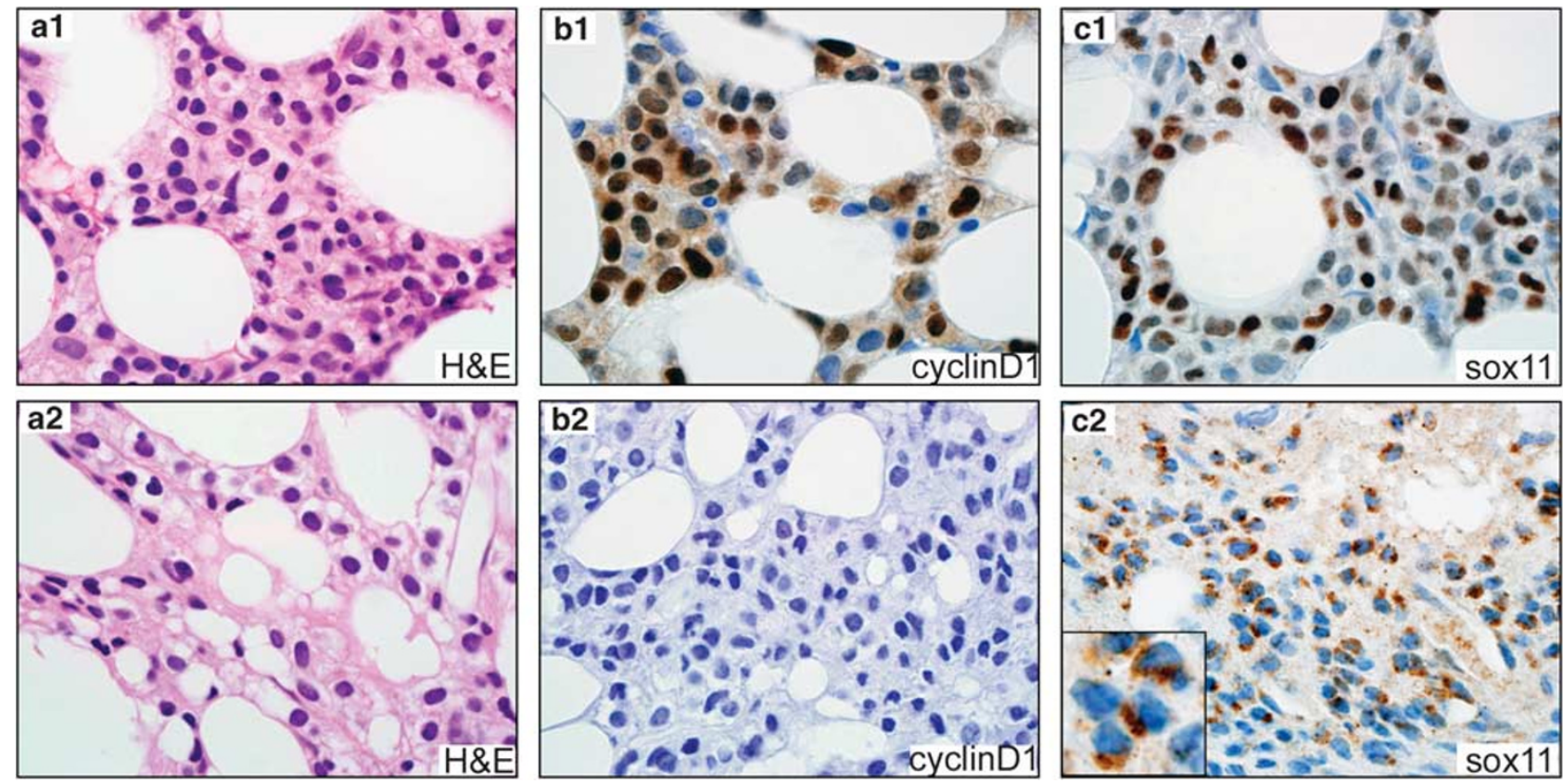

Figure 3 Sox11 expression in hairy cell leukemia. H\&E (left), immunohistochemical stains for cyclin D1 (middle) and sox11 (right) in representative cases of hairy cell leukemia $(\times 1000)$. (1a-c) Hairy cell leukemia positive for nuclear staining of cyclin D1 also showed positive nuclear staining of sox11. (2a-c): Hairy cell leukemia negative for nuclear staining of cyclin D1 was also negative for nuclear staining of sox11. Positive granular staining of sox11 was seen only in the cytoplasm.

staining of sox11 is highly specific for classical mantle cell lymphoma, but may not be a sensitive marker for variant mantle cell lymphoma.

The high association of nuclear expression of sox11 with mantle cell lymphoma shown in this study and by others raises the question about its possible association with $\mathrm{t}(11 ; 14)(\mathrm{q} 13 ; \mathrm{q} 32)$. To answer this, we examined sox11 in plasma cell myelomas as a subset of this terminally differentiated B-cell neoplasm carry the same chromosomal translocation and overexpress cyclin $\mathrm{D} 1 .^{1}$ In addition, +11 also contributes to the upregulation of cyclin D1 in this neoplasm. ${ }^{23}$ A total of 30 plasma cell myelomas were selected for the study on the basis of the FISH results. Immunohistochemical stain for cyclin D1 showed strong nuclear staining in 12 of $12(100 \%)$ cases with t(11;14), 10 of $11(91 \%)$ with +11 and in 1 of $7(14 \%)$ negative for both abnormalities. However, none of the plasma cell myelomas examined was positive for nuclear staining of sox11.

In contrast to plasma cell myelomas, no specific cytogenetic abnormality or chromosomal translocation has been described in hairy cell leukemia. ${ }^{1,24,25}$ However, cyclin D1 is overexpressed in 50-70\% cases. We showed for the first time that in addition to mantle cell lymphoma, intense nuclear staining of sox11 was also present in a subset of hairy cell leukemia and was highly associated with the overexpression of cyclin D1. However, this correlation needs to be confirmed by studies on a larger number of hairy cell leukemia cases.
As shown in this study, 3 of 57 mantle cell lymphomas were negative for nuclear sox11 staining, and 2 were analyzed by FISH and were positive for $\mathrm{t}(11 ; 14)(\mathrm{q} 13 ; \mathrm{q} 32)$. In addition, 12 cases of $\mathrm{t}(11 ; 14)$-positive plasma cell myelomas were completely negative for nuclear staining of sox11. We also demonstrated nuclear expression of sox11 in a subset of hairy cell leukemias with overexpression of cyclin D1. It is well known that the cyclin D1 overexpression in hairy cell leukemia is independent of $\mathrm{t}(11 ; 14)$. These findings indicate that although nuclear expression of sox11 is highly associated with mantle cell lymphoma, it is independent of $\mathrm{t}(11 ; 14)(\mathrm{q} 13 ; \mathrm{q} 32)$ in non-mantle cell B-cell neoplasms.

The findings of nuclear expression of sox11 in the vast majority of mantle cell lymphomas and a subset of hairy cell leukemias, but not in normal lymphoid tissue or other types of B-cell neoplasms, suggest that sox11 may be involved in the pathogenesis of these two B-cell malignancies. So far, much of the evidence linking $S O X$ genes to malignancies is correlative, and the underlying molecular mechanisms are largely unknown. ${ }^{19}$ Gene expression profiling showed that several genes related to apoptosis and to the PI3K/AKT, Wnt and transforming growth factor- $\beta$ signaling pathways were altered in mantle cell lymphoma cells when compared with naive B cells. $^{3}$ RNAi-mediated knockdown of SOX11 in neuroblastoma cells increased the expression of the proapoptotic gene BNIP3 (BclII interacting protein-1 NIP3) and decreased the expression of 
the anti-apoptotic gene TANK (TNF receptor-associated factor family member-associated NF- $\kappa$ B activator). ${ }^{16}$ Therefore, it is logical to hypothesize that sox11 may contribute to the pathogenesis and/or progression of mantle cell lymphoma and hairy cell leukemia by regulating genes involved in cell proliferation and apoptosis. ${ }^{26}$

The mechanism underlying the frequent upregulation of cyclin D1 in hairy cell leukemia is largely unknown. ${ }^{24}$ Hairy cell leukemia lacks the $t(11 ; 14)$ translocation which causes overexpression of cyclin D1 in mantle cell lymphoma and a subset of plasma cell myeloma. The high association between nuclear expression of sox11 and overexpression of cyclin D1 in hairy cell leukemia as shown by this study suggests a link between the transcription factor and the positive cell-cycle regulator. Multiple signaling pathways could lead to the upregulation of cyclin D1, including Wnt and PI3K/AKT pathways. $^{26,27}$ The activation of Wnt signaling pathway facilitates the accumulation and nuclear translocation of $\beta$-catenin and subsequently induces the target gene expression. CCND1 encoding cyclin D1 is one of the target genes. ${ }^{26}$ It has been shown that sox4 and sox11 enhance Wnt signaling activity, whereas sox17 antagonizes this activity in gut epithelial cells. However, sox 4 and sox17 were more extensively investigated in that study. ${ }^{28}$ The PI3K/ AKT pathway may also have a role in hairy cell leukemia cell proliferation. ${ }^{29}$ Interestingly, activation of this pathway not only promotes the antiapoptotic signaling but also increases the expression of cyclin D1. ${ }^{27}$ Further investigation of the possibility of activation of these pathways by sox11 may help to uncover the molecular mechanisms underlying the upregulation of cyclin D1 in hairy cell leukemia.

In summary, our study showed that the nuclear expression of the neuronal transcription factor sox11 was highly associated with mantle cell lymphoma but independent of $t(11 ; 14)$ (q13;q32) in non-mantle cell B-cell neoplasms. We showed that it was present in a subset of hairy cell leukemia and was associated with overexpression of cyclin D1. Our results indicate that sox11 may not only be a valuable diagnostic marker for mantle cell lymphoma, but may also have a functional role in the development of mantle cell lymphoma and hairy cell leukemia. Further cellular and molecular studies will help improve our understanding of the mechanisms involved in the pathogenesis and/or progression of the two B-cell malignancies, as well as the roles of sox11 in these processes.

\section{Acknowledgements}

We thank Chunyan Luan (Pathology Core Facilities, Robert H Lurie Comprehensive Cancer Center of Northwestern University) and Janet Wilson
(Immunohistochemistry Laboratory, Department of Pathology, Northwestern Memorial Hospital) for their excellent work with the immunohistochemistry.

\section{Disclosure/conflict of interest}

The authors declare no conflict of interest.

\section{References}

1 Swerdlow SH, Campo E, Harris NL, et al. WHO Classification of Tumours of Haematopoietic and Lymphoid Tissues. 4th edn IARC: Lyon, 2008.

2 Jares P, Colomer D, Campo E. Genetic and molecular pathogenesis of mantle cell lymphoma: perspectives for new targeted therapeutics. Nat Rev Cancer 2007;7:750-762.

3 Rizzatti EG, Falcao RP, Panepucci RA, et al. Gene expression profiling of mantle cell lymphoma cells reveals aberrant expression of genes from the PI3KAKT, WNT and TGFbeta signalling pathways. Br J Haematol 2005;130:516-526.

4 Ek S, Andreasson U, Hober S, et al. From gene expression analysis to tissue microarrays: a rational approach to identify therapeutic and diagnostic targets in lymphoid malignancies. Mol Cell Proteomics 2006;5:1072-1081.

5 Ortega-Paino E, Fransson J, Ek S, et al. Functionally associated targets in mantle cell lymphoma as defined by DNA microarrays and RNA interference. Blood 2008;111:1617-1624.

6 Ek S, Dictor M, Jerkeman M, et al. Nuclear expression of the non B-cell lineage Sox11 transcription factor identifies mantle cell lymphoma. Blood 2008; 111:800-805.

7 Wang X, Asplund AC, Porwit A, et al. The subcellular Sox11 distribution pattern identifies subsets of mantle cell lymphoma: correlation to overall survival. Br J Haematol 2008;143:248-252.

8 Jay P, Goze C, Marsollier C, et al. The human SOX11 gene: cloning, chromosomal assignment and tissue expression. Genomics 1995;29:541-545.

9 Wegner M. From head to toes: the multiple facets of Sox proteins. Nucleic Acids Res 1999;27:1409-1420.

10 Kiefer JC. Back to basics: Sox genes. Dev Dyn 2007;236:2356-2366.

11 Sock E, Rettig SD, Enderich J, et al. Gene targeting reveals a widespread role for the high-mobility-group transcription factor Sox11 in tissue remodeling. Mol Cell Biol 2004;24:6635-6644.

12 Hargrave M, Wright E, Kun J, et al. Expression of the Sox11 gene in mouse embryos suggests roles in neuronal maturation and epithelio-mesenchymal induction. Dev Dyn 1997;210:79-86.

13 van de Wetering M, Oosterwegel M, van Norren K, et al. Sox-4, an Sry-like HMG box protein, is a transcriptional activator in lymphocytes. EMBO J 1993;12:3847-3854.

14 Schilham MW, Oosterwegel MA, Moerer $\mathrm{P}$, et al. Defects in cardiac outflow tract formation and pro-Blymphocyte expansion in mice lacking Sox-4. Nature 1996;380:711-714. 
15 Dy P, Penzo-Mendez A, Wang H, et al. The three SoxC proteins-Sox4, Sox11 and Sox12-exhibit overlapping expression patterns and molecular properties. Nucleic Acids Res 2008;36:3101-3117.

16 Jankowski MP, Cornuet PK, McIlwrath S, et al. SRYbox containing gene 11 (Sox11) transcription factor is required for neuron survival and neurite growth. Neuroscience 2006;143:501-514.

17 Bergsland $M$, Werme $M$, Malewicz $M$, et al. The establishment of neuronal properties is controlled by Sox4 and Sox11. Genes Dev 2006;20:3475-3486.

18 Kim DK, Han SB, Hong ST, et al. Expression of Sox11 and Brn transcription factors during development and following transient forebrain ischemia in the rat. Neurosci Lett 2008;433:259-264.

19 Dong C, Wilhelm D, Koopman P. Sox genes and cancer. Cytogenet Genome Res 2004;105:442-447.

20 Lee CJ, Appleby VJ, Orme AT, et al. Differential expression of SOX4 and SOX11 in medulloblastoma. J Neurooncol 2002;57:201-214.

21 Weigle B, Ebner R, Temme A, et al. Highly specific overexpression of the transcription factor SOX11 in human malignant gliomas. Oncol Rep 2005;13:139-144.

22 Shin MS, Fredrickson TN, Hartley JW, et al. Highthroughput retroviral tagging for identification of genes involved in initiation and progression of mouse splenic marginal zone lymphomas. Cancer Res 2004;64:4419-4427.

23 Lesage D, Troussard X, Sola B. The enigmatic role of cyclin D1 in multiple myeloma. Int $\mathrm{J}$ Cancer 2005;115:171-176.

24 de Boer CJ, Kluin-Nelemans JC, Dreef E, et al. Involvement of the CCND1 gene in hairy cell leukemia. Ann Oncol 1996;7:251-256.

25 Bosch F, Campo E, Jares P, et al. Increased expression of the PRAD-1/CCND1 gene in hairy cell leukaemia. Br J Haematol 1995;91:1025-1030.

26 Klein EA, Assoian RK. Transcriptional regulation of the cyclin D1 gene at a glance. J Cell Sci 2008;121:3853-3857.

27 Liang J, Slingerland JM. Multiple roles of the PI3K/ PKB (Akt) pathway in cell cycle progression. Cell Cycle 2003;2:339-345.

28 Sinner D, Kordich JJ, Spence JR, et al. Sox17 and Sox4 differentially regulate beta-catenin/T-cell factor activity and proliferation of colon carcinoma cells. Mol Cell Biol 2007;27:7802-7815.

29 Tiacci E, Liso A, Piris M, et al. Evolving concepts in the pathogenesis of hairy-cell leukaemia. Nat Rev Cancer 2006;6:437-448. 